\title{
Hyperbaric treatment of cerebral air embolism in an infant with cyanotic congenital heart disease
}

\author{
[Le traitement hyperbare d'une embolie gazeuse cérébrale chez un enfant atteint \\ de cardiopathie cyanogène congénitale]
}

Kenneth M. LeDez MD FRCPC, Geoff Zbitnew MD

Purpose: Infants with cyanotic congenital heart disease are at risk for cerebral arterial gas embolism (CAGE) from iv infusion lines. Concern about the hazards and difficulty of caring for such patients inside a hyperbaric chamber may deter referral. We report a complex case in which a small infant was managed successfully using a modified hyperbaric oxygen treatment (HBOT) schedule.

Clinical features: A four-month-old $6.19 \mathrm{~kg}$ male infant with a recent Glenn shunt for double-outlet right ventricle had a seizure and became unstable immediately after an iv drug infusion. The patient was sedated, intubated and ventilated and dobutamine was commenced. A computerized tomography (CT) scan performed ten hours later demonstrated three intracranial air bubbles. About ten hours later the patient was referred for HBOT which commenced soon afterwards in a multiplace chamber. Since the rightto-left shunt would greatly increase the risk of decompression illness from breathing hyperbaric air HBOT was modified by the use of an abbreviated schedule at reduced pressure. Two 90-min HBOT sessions were administered within $24 \mathrm{hr}$ at 38 feet of seawater pressure, equivalent to 2.15 atmospheres absolute without any air break. During treatment the infant was ventilated using an Oxford Penlon ventilator. A subsequent CT scan demonstrated the absence of air. After extubation he appeared neurologically intact except for some weakness of the left arm.

Conclusion: Hyperbaric oxygen may be utilized to treat CAGE in small infants with right-to-left shunt and should be commenced promptly.

Objectif : Les enfants atteints de cardiopathie cyanogène congénitale risquent de subir une embolie gazeuse de l'artère cérébrale (EGAC) à partir des cathéters pour perfusion iv. Les préoccupations concernant les dangers et la difficulté de soigner ces patients en chambre hyperbare peuvent retarder les demandes de consultation. Nous présentons un cas complexe de traitement réussi en utilisant un programme modifié d'oxygénothérapie hyperbare (OTHB).
Éléments cliniques : Un bébé de quatre mois, de sexe masculin, pesant $6,19 \mathrm{~kg}$, ayant subi récemment une opération de Glenn pour un ventricule droit à double issue, a été victime d'une convulsion et son état est devenu instable immédiatement après la perfusion iv d'un médicament. Nous avons donné un sédatif, intubé et ventilé le patient et amorcé un traitement à la dobutamine. Une tomographie réalisée dix heures plus tard, a montré trois bulles d'air intracrâniennes. Dix heures plus tard environ, le patient a été transféré pour une OTHB, commencée peu après dans une chambre multiplace. Comme le shunt droite-gauche pouvait augmenter beaucoup le risque de maladie de décompression en respirant de l'air hyperbare, l'OTHB a été modifiée par un programme abrégé à pression réduite. II y a eu deux sessions d'OTHB de 90 min en 24 h à 38 pieds de pression (niveau de la mer), équivalente à 2, 15 atmosphères absolues, sans coupure d'air. Pendant le traitement, l'enfant était ventilé avec un appareil Oxford Penlon. Une deuxième tomographie a montré l'absence d'air. Après l'extubation, l'enfant ne présentait aucune déficience neurologique, sauf pour une légère faiblesse du bras gauche.

Conclusion : L'oxygène hyperbare peut être utilisé pour traiter I'EGAC chez de jeunes enfants qui présentent un shunt droite-gauche et devrait être administré sans tarder.

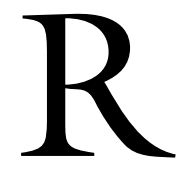

IGHT-TO-LEFT shunt (RLS) is a contraindication to diving because of an increased risk of decompression illness and cerebral arterial gas embolism (CAGE). ${ }^{1}$ Treatment schedules for CAGE require prolonged hyperbaric oxygen treatment (HBOT) at high pressures and this necessitates "air breaks" (to prevent oxygen seizures) $)^{2}$ but this is a concern in patients with RLS. Unfortunately, CAGE may occur in such patients due to iv therapy or medical procedures. ${ }^{3-5}$ Treating critically ill small babies in a hyper-

From the Department of Anesthesia, Memorial University of Newfoundland, St. John's, Newfoundland, Canada.

Address correspondence to: The Department of Anesthesia, Memorial University of Newfoundland, Health Sciences Centre, 300 Prince

Phillip Drive, St. John’s, Newfoundland AlB 3V6, Canada. Phone: 709-777-6541; Fax: 709-777-6506; E-mail: kledez@mun.ca Accepted for publication August 10, 2004.

Revision accepted January 14, 2005. 
baric chamber poses special challenges and there is little published experience of these situations, ${ }^{6}$ especially pertaining to children with cyanotic congenital heart disease (CCHD). ${ }^{7-9}$ We describe HBOT of an infant with complex CCHD and CAGE.

\section{Clinical features}

A male $3.28-\mathrm{kg}$ baby was born at 37 weeks gestation by Cesarean section in a peripheral hospital. Grunting and persistent cyanosis were noted and a blood gas during a hyperoxia test demonstrated $\mathrm{PaO}_{2}$ of $35.3 \mathrm{mmHg}$. The baby was intubated, ventilated, and commenced on prostaglandin El prior to air transportation to the neonatal intensive care unit at the author's tertiary care teaching centre. Echocardiography findings included a large atrioventricular (AV) septal defect with transposition of the great vessels, good ventricular contractility and $\mathrm{AV}$ valve function and critical pulmonary stenosis. The patent ductus arteriosus (PDA) was supplying the majority of pulmonary blood flow. The patient was transferred when three days old by air to the regional pediatric cardiac surgical centre.

A cranial ultrasound and neurological examination at four days of age were normal. On day five a rightsided modified Blalock-Taussig procedure with PDA ligation was performed ${ }^{10}$ without complications. At three months and three weeks of age $(6.11 \mathrm{~kg})$ cardiac catheterization demonstrated: a complete AV defect; double outlet right ventricle; malposed great vessels; the inferior vena cava joined the left sided atrium via a hepatic vein; and the pulmonary veins entered the right sided atrium.

A modified (left-sided) bidirectional Glenn shunt was performed ${ }^{10}$ one week later with ligation of the previous shunt. The procedure was relatively uneventful, oxygen saturation $\left(\mathrm{SaO}_{2}\right)$ was 70 to $80 \%$ postoperatively breathing room air and he was extubated about $18 \mathrm{hr}$ later. However, four right arm focal seizures occurred (treated with benzodiazepines) over the next four days and a computerized tomography (CT) scan demonstrated a left posterior subdural hematoma and an old hemorrhage over the frontal lobes. Aspirin and ketorolac were discontinued and phenytoin was commenced.

The baby appeared well, normal feeding resumed and he was transferred back by air ambulance one week after surgery weighing $6.19 \mathrm{~kg}$. At that time a double-lumen femoral venous line remained in place due to extremely difficult vascular access but the femoral arterial line had been removed. At 3:10 a.m., approximately four hours after arrival on the ward, phenytoin and saline flush were administered through separate lumens. Shortly thereafter the baby was arch-

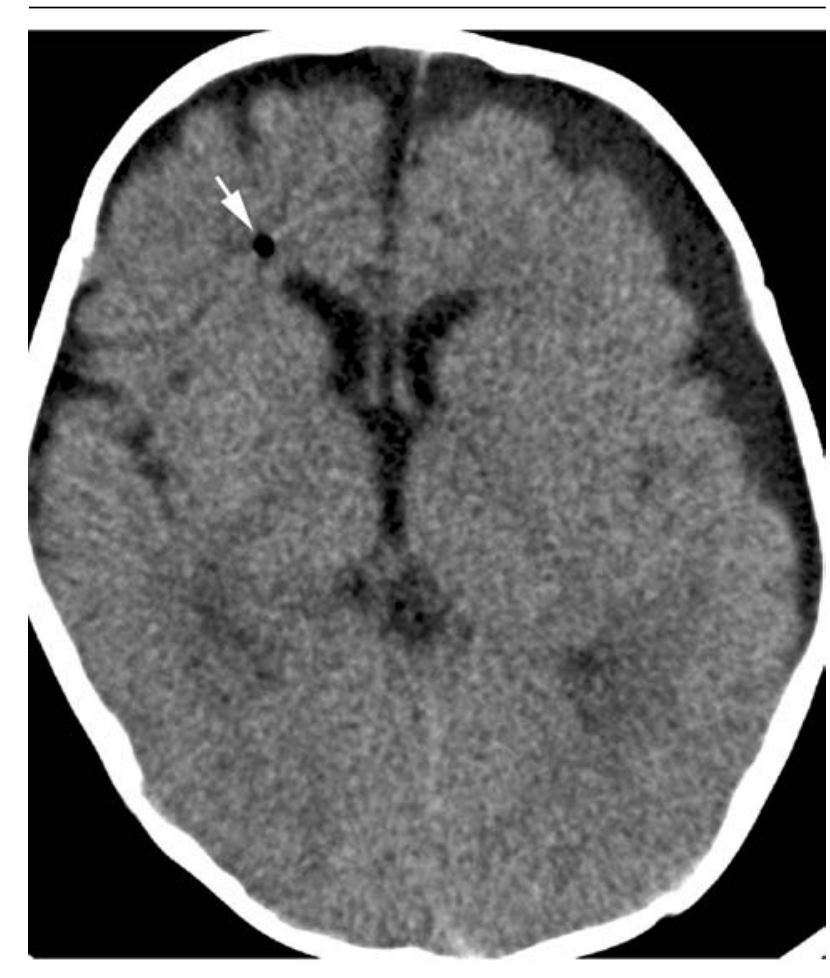

FIGURE la Computerized tomography scan of the head prior to hyperbaric oxygen treatment demonstrating a single right frontal gas bubble (arrow) measuring 3.2 by $3.5 \mathrm{~mm}$, and left hygroma.

ing his back with clenched hands and his head and eyes deviating to the right. Grunting, groaning and indrawing were noted, the $\mathrm{SaO}_{2}$ was $46 \%$ (despite $40 \%$ oxygen), respiratory rate was over 70 and heart rate was 189 . The baby received lorazepam $0.3 \mathrm{mg}$ intravenously, and was transferred to the pediatric intensive care unit (PICU). A capillary blood gas (CBG) on $100 \%$ oxygen at 05:40 demonstrated: $\mathrm{pH}$ 6.699; $\mathrm{paCO}_{2} 84.9 \mathrm{mmHg} ; \mathrm{paO}_{2} 41.8 \mathrm{mmHg}$; base excess $27.9 \mathrm{mmol} \cdot \mathrm{L}^{-1} ; \mathrm{HCO}_{3}-9.9 \mathrm{mmol} \cdot \mathrm{L}^{-1}$. Midazolam and rocuronium were administered prior to intubation with a $4.0 \mathrm{~mm}$ endotracheal tube. An echocardiography demonstrated normal shunt flow but decreased contractility. Dobutamine $4 \mu \mathrm{g} \cdot \mathrm{kg}^{-1} \cdot \mathrm{min}^{-1}$ was started and the baby's colour improved.

A CT of the head, delayed until 13:00 because the patient was considered too unstable, demonstrated a resolving subural hematoma, an air bubble in the right frontal area and two air bubbles deep in the middle of the left side of the brain (Figures la and lb). These findings and the sudden deterioration following iv infusion suggested CAGE. At approximately 23:00 


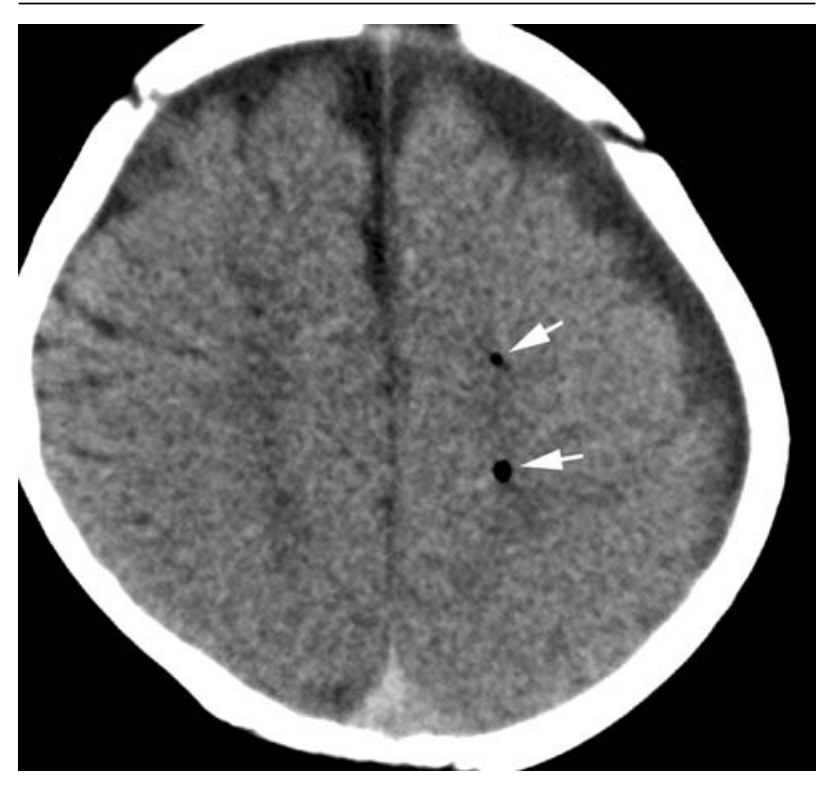

FIGURE lb Computerized tomography scan of the head prior to hyperbaric oxygen treatment demonstrating two left sided white matter gas bubbles (arrows) measuring 1.8 by $1.6 \mathrm{~mm}$ (upper bubble) and 3.2 by $2.7 \mathrm{~mm}$ (lower bubble). the patient was referred for a hyperbaric medicine opinion. Multiple attempts by three physicians to insert an arterial line were unsuccessful. A CBG at 02:00 demonstrated: $\mathrm{pH} 7.375 ; \mathrm{paCO}_{2} 33.5 ; \mathrm{paO}_{2}$ 33; base excess -4.7 ; $\mathrm{HCO}_{3}-19.1$. After detailed discussion of possible risks and written consent of the parents the patient was transferred to the hyperbaric chamber facility.

Lidocaine $2 \%$ was instilled into each external auditory canal to reduce ear pain from inevitable barotrauma (the authors decided not to delay further for an ear, nose and throat surgeon to perform a myringotomy or to do so ourselves since inexpert myringotomy is potentially more harmful than barotrauma). HBOT commenced approximately $23 \mathrm{hr}$ after the CAGE and monitoring comprised an electrocardiogram, airway pressure, exhaled volume (Wright spirometer) and manual blood pressure. Infusions (dobutamine 4 $\mu \mathrm{g} \cdot \mathrm{kg}^{-1} \cdot \mathrm{min}^{-1}$, midazolam $3 \mu \mathrm{g} \cdot \mathrm{kg}^{-1} \cdot \mathrm{min}^{-1}$, and morphine $30 \mu \mathrm{g} \cdot \mathrm{kg}^{-1} \cdot \mathrm{min}^{-1}$ ) were continued using syringe pumps. The patient was kept on an inspired oxygen concentration of $100 \%$ from the time that pressurization began. Ventilation was manual during pressurization and depressurization and was maintained using an Oxford Penlon ventilator ${ }^{11}$ with a pediatric bellows

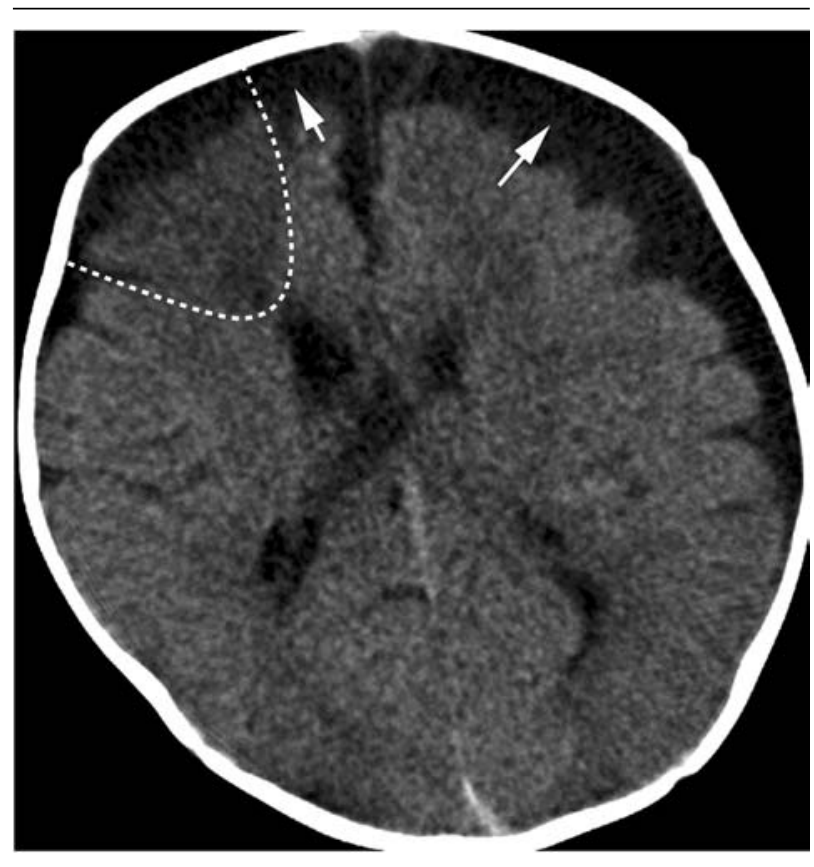

FIGURE 2 Computerized tomography scan of the head on the third day after cerebral arterial gas embolism and after hyperbaric oxygen treatment. The previously noted gas bubbles are absent and there is a possible wedge shaped area of decreased attenuation (dotted line) in the same region as the previously noted right sided gas bubble. Subdural hygromas are indicated by the arrows.

during the $90 \mathrm{~min}$ period at 38 feet of seawater (fsw) pressure. Oxygen contamination of the chamber environment (a fire hazard) was controlled by scavenging the ventilator to the "overboard dump system" and by placing a continuous suction near the patient's face to scavenge leaks from the uncuffed endotracheal tube. The baby appeared pink during HBOT but arterial blood gas analysis was not attempted because of very difficult vascular access.

On arrival in the PICU rectal temperature was $36.5^{\circ} \mathrm{C}$ and $\mathrm{CBG}$ demonstrated adequacy of ventilation during $\mathrm{HBOT}$ ( $\mathrm{pH}$ of $7.378 ; \mathrm{paCO}_{2} 36.3 ; \mathrm{paO}_{2}$ 40.1; base excess -3.2; $\mathrm{HCO}_{3}-20.9$ ). Dobutamine was stopped. A second similar HBOT undertaken about $12 \mathrm{hr}$ after the first was uneventful. A CT scan three days after the CAGE (Figure 2) demonstrated absence of air bubbles and a possible wedge shaped area of decreased attenuation on the right side. The baby was weaned from sedation and ventilation, and appeared neurologically intact with the exception of a possible subtle weakness of the left arm. Bilateral tym- 
panic membrane hemorrhages without perforation were observed after HBOT. These resolved without complications and the infant's hearing was clinically normal at the time of discharge.

Initially after discharge the patient tended to keep the left hand clenched but since then has been grasping and moving the left arm better, improving with physiotherapy, but still slightly weaker than the right.

\section{Discussion}

The combination of small vessels, RLS, rich cerebral and coronary circulations, developing organs and multiple invasive medical procedures means that small infants with CCHD are particularly susceptible to CAGE.

No randomized trial has been conducted for treatment of CAGE related to medical mishaps and it is unlikely that such a trial could be ethically undertaken. However, from examination of information from case series ${ }^{5,12}$ it is apparent that both mortality and major morbidity are much higher in the absence of HBOT and that outcome is better when it commences within six hours. ${ }^{13}$ Presentation of iatrogenic CAGE in adults includes coma, seizures, encephalopathic features, respiratory arrest, sensory and motor deficits (including hemiplegia and hemianopia), disorientation and ventricular fibrillation. ${ }^{5,12}$ Response to prompt HBOT may be dramatic and complete. ${ }^{12}$ In $75 \%$ of adults air bubbles may be seen on a CT $\operatorname{scan}^{5}$ and may persist for at least four days. ${ }^{14}$

Air embolism has been described in pediatric patients related to central and peripheral venous catheters and invasive procedures ${ }^{4,15-18}$ and is an important iatrogenic cause of morbidity and mortality. Unfortunately, HBOT has seldom been used in these cases and has not previously been reported for treatment of CAGE in infants with CCHD.

The Glenn shunt (which provides venous blood from the superior vena cava to the lung for gas exchange and prepares the pulmonary vasculature for a subsequent modified Fontan repair), ${ }^{10}$ would not be expected to alter the risk of CAGE through a femoral venous catheter. Upper body venous access might seem preferable here but air embolism leading to paraplegia has been reported from a scalp vein cannula in a term infant without CCHD. ${ }^{18}$ The cause of the hemodynamic instability in this case is uncertain but acidosis and coronary air embolism are possibilities. The cause of the subdural hemorrhages is unknown but may be related to heparinization during surgery.

HBOT is the only specific effective treatment for CAGE and its rationale includes: reduction of bubble size with increased ambient pressure (Boyles
Law); ${ }^{12,19-21}$ increased dissolved oxygen (Henry's Law $)^{21}$ and elimination of inspired nitrogen leading to enhanced diffusion gradients (Fick's Law) 22 to enable oxygenation of ischemic penumbra and accelerated elimination of bubble nitrogen; ${ }^{12,19}$ and hyperoxic vasoconstriction resulting in reduced cerebral swelling ${ }^{12}$ and decreased cardiac shunt fraction. Infants dependent upon an unstented PDA may not be suitable for HBOT since hyperoxia could stimulate closure.

CT scans, ${ }^{4,15}$ or ultrasound ${ }^{16}$ may demonstrate CAGE in infants. However, if suspected on clinical grounds HBOT should not be delayed for these investigations ${ }^{19}$ since physiologic considerations and clinical experience suggest that delays result in a worse outcome. . $^{2,12,12,19,20}$ Unstable infants with CCHD are usually cared for in tertiary care centres where HBOT is readily available. If air transportation is necessary a fixed wing aircraft must be pressurized to 1 atmosphere absolute (ATA) or a helicopter must fly below $300 \mathrm{~m}$ to avoid bubble expansion and clinical deterioration. ${ }^{20,23}$ The hyperbaric physician should be involved in transportation arrangements.

It is difficult to neurologically assess ventilated sedated newborns but increased sedation requirements soon after commencing HBOT suggested improvement. The response to HBOT for iatrogenic CAGE accords with the effectiveness found in the context of diving and submarine escape training. ${ }^{2,19,20}$ The usual treatment schedules for CAGE are US Navy tables 6A (maximum depth 165 fsw, 6 ATA) or 6 (maximum depth $60 \mathrm{fsw}, 2.8$ ATA). ${ }^{2}$ These schedules take about five to $11 \mathrm{hr}$ and in order to reduce the incidence of oxygen toxicity "air breaks" are required. In this case $38 \mathrm{fsw}$ (2.15 ATA) for only 90 min was chosen in order to permit use of a 40 fsw dive table for staff decompression planning (the need for possible emergency depressurization of the chamber before decompression stops could be completed was anticipated in this unstable patient) while also minimizing the risks of decompression illness in the patient by eliminating air breaks. More prolonged continuous oxygen would have entailed an unacceptable risk of hyperoxic seizures.

Multiplace chambers are better suited for the treatment of CAGE because of greater pressure capabilities and ability for hands-on critical care. However, monoplace chambers (which have limited pressure capabilities) have been used for CAGE. Given the complex circumstances, the unusual HBOT schedule (somewhat similar to published monoplace regimes ${ }^{23}$ except for lesser pressure) was justified to ensure patient and staff safety and considering percentage bubble volume change is greatest within 2 ATA pressure. ${ }^{2}$ 
Syringe pumps were used during the first HBOT for safety reasons but were briefly non-functional after HBOT and had to be serviced. For this reason microdrip sets were used for manual drug infusions during the second treatment even though this is more difficult in small infants. Most infusion pumps are unacceptable for use under hyperbaric conditions. ${ }^{24}$

Safe HBOT for a critically-ill infant requires sufficient specially trained personnel; here this comprised an adult intensive care nurse, a pediatric respiratory therapist and a hyperbaric physician inside and a hyperbaric physician, adult critical care nurse, pediatric intensive care nurse, pediatric intensivist and technical staff (supervisor and chamber operator) outside the chamber.

In summary, HBOT is feasible when indicated even in small infants with CCHD and should be instituted promptly for CAGE, without delays for CT or other investigations; air bubbles may persist for many hours; CAGE must be considered whenever sudden deterioration occurs in patients with RLS; modification of usual hyperbaric treatment schedules may be necessary; and HBOT may be effective even when applied late. However, although the bubbles on CT resolved after HBOT in this case, the maximum delay after which HBOT is no longer worthwhile remains unknown, as is the degree of benefit in this particular patient. Serious complications of HBOT are unusual but may arise if undertaken inappropriately or without due care. ${ }^{25}$ Experienced highly trained staff and careful planning are essential to enable safe HBOT for small infants with CCHD.

\section{Acknowledgements}

The authors would like to thank: Dr. Angela Pickles for providing and interpreting CT scans; Sylvia Ficken of Health Sciences Information and Media Service for work on the CT scan images; Fronie Squibb for secretarial assistance; Dale Decker (diving supervisor) and the technical, nursing and respiratory therapy staff at the MEDICOR hyperbaric chamber facility; Dr. Debbie Reid and the nursing and respiratory therapy staff of the Pediatric Intensive Care Unit; and the parents of the child described in this report for their assistance.

\section{References}

1 Bove AA. Fitness to dive. In: Brubakk AO, Neuman TS (Eds). Bennett and Elliott's Physiology and Medicine of Diving, 5th ed. Edinburgh: Saunders; 2003: 700-17.

2 Moon RE, Gorman DF. Treatment of the decompression disorders. In: Brubakk AO, Neuman TS (Eds). Bennett and Elliott's Physiology and Medicine of
Diving, 5th ed. Edinburgh: Saunders; 2003: 600-50.

3 Messina AG, Leslie J, Gold J, Topkins MJ, Devereux RB. Passage of microbubbles associated with intravenous infusion into the systemic circulation in cyanotic congenital heart disease: documentation by trans-

esophageal echocardiography. Am J Cardiol 1987; 59: 1013-4.

4 Robinson A. Air embolism following CAT scan in a patient with hypoplastic left heart syndrome. Pediatr Cardiol 2003; 24: 186.

5 Heckmann JG, Lang CJ, Kindler K, Huk W, Erbguth FJ, Neundorfer B. Neurologic manifestations of cerebral air embolism as a complication of central venous catheterization. Crit Care Med 2000; 28: 1621-5.

6 Keenan HT, Bratton SL, Norkool DM, Brogan TV, Hampson NB. Delivery of hyperbaric oxygen therapy to critically ill, mechanically ventilated children. J Crit Care 1998; 13: 7-12.

7 Vazquez RL, Spahr RC. Hyperbaric oxygen use in neonates. A report of four patients. Am J Dis Child 1990; 144: 1022-4.

8 Waisman D, Shupak A, Weisz G, Melamed $\Upsilon$. Hyperbaric oxygen therapy in the pediatric patient: the experience of the Israel Naval Medical Institute. Pediatrics 1998; 102: E53.

9 Joseph MC, McAuley C, Potts MW. A study of the effects of hyperbaric oxygen in infants with cyanotic heart disease. Guys Hosp Rep 1966; 115: 73-9.

10 Hickey PR, Wessel DL. Anesthesia for treatment of congenital heart disease In: Kaplan JA (Ed.). Cardiac Anesthesia, 2nd ed, volume 2. Orlando: Grune \& Stratton Inc; 1987: 635-711.

11 Blanch PB, Desautels DA, Gallagher TJ. Deviations in function of mechanical ventilators during hyperbaric compression. Respir Care 1991; 36: 803-14.

12 Murphy BP, Harford FJ, Cramer FS. Cerebral air embolism resulting from invasive medical procedures. Treatment with hyperbaric oxygen. Ann Surg 1985; 201: 242-5.

13 Blanc P, Boussuges A, Henriette K, Sainty JM, Deleflie $M$. Iatrogenic cerebral air embolism: importance of an early hyperbaric oxygenation. Intensive Care Med 2002; 28: 559-63.

14 Iwami O, Kawamura J, Hashimoto S, Nakamura M, Suenaga T. Cerebral air embolism (Letter). Am J Neuroradiol 1990; 11: 1166.

15 Voorhies RM, Fraser RA. Cerebral air embolism occurring at angiography and diagnosed by computerized tomography. Case report. J Neurosurg 1984; 60: 177-8.

16 Daneman A, Abou-Reslan W, Jarrin J, Traubici J, Hellmann J. Sonographic appearance of cerebral vascular air embolism in neonates: report of two cases. Can 
Assoc Radiol J 2003; 54: 114-7.

17 Levy I, Mosseri R, Garty B. Peripheral intravenous infusion - another cause of air embolism. Acta Paediatr 1996; 85: 385-6.

18 Willis J, Duncan C, Gottschalk S. Paraplegia due to peripheral venous air embolus in a neonate: a case report. Pediatrics 1981; 67: 472-3.

19 Neuman TS. Arterial gas embolism and pulmonary barotrauma. In: Brubakk AO, Neuman TS (Eds).

Bennett and Elliott's Physiology and Medicine of Diving, 5th ed. Edinburgh: Saunders; 2003: 557-77.

20 Walker R. Pulmonary barotrauma. In: Edmonds C, Lowry C, Pennefather J, Walker R (Eds). Diving and Subaquatic Medicine, 4th ed. London: Arnold; 2002: 55-71.

21 Pennefather J. Physics and physiology. In: Edmonds C, Lowry C, Pennefather J, Walker R (Eds). Diving and Subaquatic Medicine, 4th ed. London: Arnold; 2002: 11-22.

22 Parbrook GD, Davis PD, Parbrook EO. Diffusion and osmosis. In: Parbrook GD, Davis PD, Parbrook EO (Eds). Basic Physics and Measurement in Anaesthesia, 3rd ed. Oxford: Butterworth Heinemann; 1994: 88-101.

23 Hart GB, Strauss MB, Lennon PA. The treatment of decompression sickness and air embolism in a monoplace chamber. J Hyperb Med 1986; 1: 1-7.

24 Lavon H, Shupak A, Tal D, et al. Performance of infusion pumps during hyperbaric conditions.

Anesthesiology 2002; 96: 849-54.

25 Nuthall G, Seear M, Lepawsky M, Wensley D, Skippen P, Hukin J. Hyperbaric oxygen therapy for cerebral palsy: two complications of treatment. Pediatrics 2000; 106. URL available at http://pediatrics.org/cgi/content/full/106/6/e80. 